\title{
Quality of Life in Methadone Maintenance Treated Patients in Iran
}

\author{
Shahrokh Aghayan, ${ }^{1}$ Mohammad Amiri, ${ }^{2}$ Reza Chaman, ${ }^{3}$ and Ahmad Khosravi ${ }^{4,}$ \\ ${ }_{1}^{1}$ Department of Psychiatry, Imam Hossein Hospital, Shahroud University of Medical Sciences, Shahroud, IR Iran \\ Department of Psychiatry, Imam Hossein Hospital, Shahroud University of Medical Sciences, Shahroud, IR Iran
${ }^{2}$ Department of Public Health, School of Public Health, Shahroud University of Medical Sciences, Shahroud, IR Iran \\ ${ }_{3}$ Department of Public Health, School of Public Health, Shahroud University of Medical Sciences, Shahro
Department of Social Medicine, Faculty of Medicine, Yasuj University of Medical Sciences, Yasuj, IR Iran \\ ${ }^{4}$ Center for Health Related Social and Behavioral Sciences Research, Shahroud University of Medical Sciences, Shahroud, IR Iran \\ ${ }^{*}$ Corresponding author: Ahmad Khosravi, Center for Health Related Social and Behavioral Sciences Research, Shahroud University of Medical Sciences, Shahroud, IR Iran. \\ Tel: +98-2332374350, Fax: +98-2332365588, E-mail: khosravi2000us@yahoo.com
}

Received 2014 September 4; Revised 2015 February 1; Accepted 2015 February 18.

\begin{abstract}
Background: Measurement of life quality as an index of health status has a widespread application in health care domain.

Objectives: The current study aimed to determine the quality of life of referents to addiction cessation centers of Iran.

Patients and Methods: In this cross-sectional study, 988 addicts who had referred to addiction cessation centers in Shahroud were studied through SF-36 questionnaire. The data were analyzed using linear regression in structural equation modeling and STATA 12 statistical software.

Results: The mean \pm SD age of the participants was $41.2 \pm 11.8$ years. Most of the referents used smoking followed by eating method of opium abuse. The mean \pm SD score of life quality was $67.8 \pm 17.2$, the mean \pm SD score of life quality in physical health dimension was $76.9 \pm$ 26.7 , and the mean \pm SD score in mental health dimension was $64.5 \pm 18.4$. Univariate analysis showed a significant relationship between life quality and gender, place of residence, education, occupation, marital status, and income $(\mathrm{P} \leq 0.05)$. However, in multivariate analysis a significant relationship was observed only between gender, socioeconomic status, and quality of life score.

Conclusions: Although most studies have reported low and weak quality of life in addicts, the findings of this study shows that the life quality score of addicts is rather good. It seems that the maintenance treatment that addicts receive in addiction cessation centers has been effective in improving the quality of life of the patients. Hence, expanding methadone treatment centers can play a leading role in the improvement of life quality in addicts.
\end{abstract}

Keywords: Quality of Life, Behavior, Addictive, Methadone

\section{Background}

In recent years, the quality of life has been considered an important index in medical research for evaluating the individual health status and for decision making and judgment about the general health of the society, as well as finding the main problems in different dimensions of life (1). Quality of life possesses different dimensions such as physical health, mental health, economic conditions, personal beliefs, and interaction with the environment $(1,2)$. Also, it is regarded very important, as it includes several dimensions of the individual such as physiological aspects, performance, and the existence (3). The quality of life is so important that the current century is called the century of improving life quality (not only surviving) and health status $(4,5)$. Life quality confines not only to the health status aspects, but also many other factors; however, health status is the core and the prerequisite of a good quality of life $(6,7)$. Some scholars believe that life quality is the individual's evaluation of his or her health status and satisfaction gained from this understanding (8). The World Health Organization has defined quality of life as the understanding that people have of their life situation in their cultural context and value systems which is related to their goals, expectation, and criteria in their lives (9). Therefore, quality of life can be defined as the physical, mental, and social welfare (such as happiness, satisfaction, pride, health, economic status, educational opportunities, and so on) which is understood by an individual or group $(7,9)$. Health-related quality of life (HRQOL) is a patient's perception of how his or her health status affects physical, psychological and social functioning, and well-being (10).

Addiction, substance dependence and its illicit trade are nowadays one of the major concerns and health threatening factors in the world $(11,12)$. Risk factors of narcotic drug abuse include family conflicts, education problems, and simultaneous occurrence of mental disorders such as depression and mood changes, drug abuse by parents and peers, and early onset of cigarette smoking. The more risk factors a person has, the higher would be the probability of drug abuse for that person (13). In patients, life quality refers to a good situation which reflects the physical, mental and social status of the person. Negative consequences of the mental status (depression, anxiety, and collapse of

Copyright (C) 2015, Zahedan University of Medical Sciences. This is an open-access article distributed under the terms of the Creative Commons Attribution-NonCommercial 4.0 International License (http://creativecommons.org/licenses/by-nc/4.0/) which permits copy and redistribute the material just in noncommercial usages, provided the original work is properly cited. 
family relationship), and physical status (bodily pain and inertia) of addiction are associated with drug abuse. These consequences result in the reduction of life quality and satisfaction in substance dependent people (14-16).

According to WHO report in 2008, 200 million people in the world were opioid dependent and Iran is also exposed to this social problem because of its geographical position $(17,18)$. Drug dependence is more common among men and even some studies report that the prevalence of addiction among men is 15 times more than that among women in Iran. The highest frequency of addiction is also in 20 - 35 years age group (17).

In recent years, a lot of attention has been paid to the health status and life quality, especially of the addicts (19, 20 ). The results of various studies indicate that the quality of life of addicts is lower than that of normal people $(12,14$ $16,21,22)$. Some studies have also shown that methadone and buprenorphine maintenance treatments have had positive effects on the life quality of the addicts (23-27).

\section{Objectives}

Therefore, the current study aimed to determine the life quality of the referents to the addiction cessation centers in Shahroud in the northeast of Iran and its affecting factors.

\section{Patients and Methods}

In this cross-sectional study, out of 26 methadone maintenance treatment centers in Shahroud, 18 centers were randomly selected in 2013 and all patients in these centers were included in the study through census method. The data collection instruments included a 10-item general questionnaire and SF-36 questionnaire which had already been validated by Montazeri and colleagues (28). Their study showed that the Iranian version of SF-36 is a reliable and valid measure of health-related quality of life among the general population. The Cronbach's alpha coefficient of all 8 scales of SF-36, range from 0.77 to 0.90 . Factor analysis identified two principle components that jointly accounted for $65.9 \%$ of the variance (28). Quality of Life Questionnaire (SF-36) is a general questionnaire which is used for assessing the health-related quality of life of people and addicts. SF-36 includes two general scales of physical health and mental health. These 2 scales comprise 8 subscales of physical functioning, role limitations due to physical health, bodily pain, general health, vitality, social functioning, role limitations due to emotional problems, and mental health. The questionnaire was administered to the participants and after the purpose of the study was explained to them, they completed the questionnaire. In case the participant was illiterate or low-literate, the questionnaire was completed by a trained interviewer.

The data were analyzed by Chi-square and One-way ANOVA to test the relationships between life quality and demographic features. The relationships between influencing factors and life quality were tested through linear regression in structural equation modeling (SEM).
Moreover, socioeconomic status of the participants was estimated based on variables such as income, residence, education, and occupation using SEM. The confidence interval in the study was 95\% and the significance level was considered 0.05 .

\section{Results}

The mean \pm SD age of the participants was $41.1 \pm 11.8$ years. Most of the participants were men (94.5\%) and married (82.5\%). About $64.7 \%$ of the participants were city-dwellers. Around $18.2 \%$ of the participants were illiterate and 9.3\% had university degrees. Opium was the major substance (35.3\%) used by the participants before they referred to methadone maintenance treatment (MMT) centers. Most of the referents before referring to the centers used smoking method (41.8\%) and eating method (31.2\%) of the opium. About $18 \%$ used both smoking and eating methods and $10.9 \%$ used injection simultaneously with other methods. Most of the participants after referring to the treatment centers used methadone ( $86.3 \%$ ), followed by opium syrup (12.6\%) and buprenorphine (0.9\%). The mean \pm SD period of drug abuse was $135.2 \pm 104.5$ months and the median period of drug abuse was 120 months and the interquartile range was 60 - 180. The shortest period of drug abuse was 3 months and the longest was 720 months. The mean \pm SD period of receiving methadone maintenance treatment was $14.8 \pm 16.1$ months. The mean \pm SD score of quality of life among the participants was $67.8 \pm 17.2$. The mean \pm SD score of quality of life in the physical health domain was $68.6 \pm 19.4$ and in mental health domain $64.8 \pm 18.4$. The highest mean \pm SD score of quality of life belonged to physical functioning $76.9 \pm 26.7$ and the lowest mean \pm SD belonged to general health as $60.5 \pm 17.5$ followed by vitality $62 \pm 18.1$ (Table 1 ).

Comparison of the scores of life quality of the two genders showed a significant difference in all dimensions $(\mathrm{P} \leq$ $0.05)$ so that the scores of men in all subscales were higher. Table 2 shows the mean scores of quality of life, physical health, and mental health based on the variables under study.

The comparison of quality of life mean scores of employed and unemployed people in different subscales shows that the mean scores of vitality, physical health, mental health, social functioning, bodily pains, general health, total quality of life of employed participants were higher than those of the unemployed ones $(\mathrm{P}<0.05)$.

Moreover, the results showed that education has a significant influence on the scores of physical health, life quality, bodily pain, and general health subscales. The post hoc test of Tukey showed that participants with university degrees had higher levels of life quality. A significant relationship was also observed between marital status and all dimensions of quality of life $(\mathrm{P} \leq 0.05)$. The post hoc Tukey test showed that married participants had a better life quality in all dimensions.

One-way ANOVA also showed a significant relationship between income and all subscales of life quality ( $P$ 
$\leq 0.05)$. A significant relationship was also observed between the housing status and all subscales of life quality except physical functioning $(\mathrm{P}=0.18)$. The mean score of role limitation due to physical health and role limitation due to emotional functioning were observed to be 0.65 and 0.099 , respectively.

The multivariate analysis of the relationships of socio- economic status, age, gender, duration of drug abuse with quality of life showed that in the final model, significant relationships exist between quality of life and gender and socioeconomic status. The results indicated that addicted women had a lower quality of life than men and people with higher socioeconomic status have higher quality of life $(\mathrm{B}=0.18)$ (Table 3$)$.

\begin{tabular}{lc}
\hline Table 1. Quality of Life Subscales Scores in Methadone Maintenance Treated Patients in Iran & \multicolumn{1}{c}{ Mean \pm SD $^{\mathrm{a}}$} \\
\hline Variables & $76.86 \pm 26.70$ \\
\hline Physical functioning & $63.77 \pm 36.60$ \\
Physical role & $73.45 \pm 23.77$ \\
Bodily pain & $60.47 \pm 17.50$ \\
General health & $61.98 \pm 18.08$ \\
Vitality & $69.99 \pm 21.32$ \\
Social functioning & $64.78 \pm 38.23$ \\
Role emotional & $62.26 \pm 18.78$ \\
Mental health & $68.64 \pm 19.45$ \\
PCS & $64.75 \pm 18.42$ \\
MCS & $67.8 \pm 17.2$ \\
SF-36 (Quality of Life) &
\end{tabular}

Table 2. Comparison of Mean Scores of Quality of Life According to Demographic Characteristics in Methadone Maintenance Treated Patients in Iran $^{\mathrm{a}, \mathrm{b}}$

\begin{tabular}{|c|c|c|c|c|}
\hline Variables & No. of Subjects & PCS & MCS & SF-36 \\
\hline \multicolumn{5}{|l|}{ Gender } \\
\hline Male & 934 & $69.24 \pm 19.52$ & $65.34 \pm 18.53$ & $68.30 \pm 17.31$ \\
\hline Female & 54 & $58.21 \pm 14.67$ & $54.67 \pm 12.94$ & $58.55 \pm 12.03$ \\
\hline P Value & & 0.001 & 0.001 & 0.001 \\
\hline \multicolumn{5}{|l|}{ Residence } \\
\hline Urban & 639 & $70.81 \pm 19.72$ & $65.94 \pm 19.86$ & $69.57 \pm 17.70$ \\
\hline Rural & 349 & $64.66 \pm 18.32$ & $62.58 \pm 15.25$ & $64.48 \pm 15.76$ \\
\hline PValue & & 0.001 & 0.006 & 0.001 \\
\hline \multicolumn{5}{|l|}{ Education } \\
\hline Illiterate & 72 & $64.28 \pm 18.45$ & $63.98 \pm 16.59$ & $65.22 \pm 15.59$ \\
\hline$\leq$ Diploma & 824 & $68.34 \pm 19.37$ & $64.37 \pm 18.23$ & $67.41 \pm 17.15$ \\
\hline Academic & 92 & $74.69 \pm 19.71$ & $68.76 \pm 21.03$ & $79.99 \pm 18.06$ \\
\hline PValue & & 0.002 & 0.089 & 0.005 \\
\hline \multicolumn{5}{|l|}{ Job } \\
\hline Unemployed & 87 & $60.84 \pm 20.41$ & $58.89 \pm 17.27$ & $61.13 \pm 17.05$ \\
\hline Employed & 901 & $69.39 \pm 19.20$ & $65.32 \pm 18.44$ & $68.41 \pm 17.09$ \\
\hline PValue & & 0.001 & 0.002 & 0.001 \\
\hline \multicolumn{5}{|l|}{ Marital status } \\
\hline Single & 131 & $65.02 \pm 19.73$ & $60.41 \pm 18.88$ & $64.61 \pm 16.87$ \\
\hline Married & 815 & $70.05 \pm 18.96$ & $66.20 \pm 17.96$ & $69.09 \pm 16.84$ \\
\hline Divorced & 42 & $52.50 \pm 19.67$ & $50.12 \pm 17.67$ & $51.97 \pm 16.39$ \\
\hline P Value & & 0.001 & 0.001 & 0.001 \\
\hline \multicolumn{5}{|l|}{ Home status } \\
\hline Personal & 498 & $69.72 \pm 18.99$ & $66.50 \pm 17.42$ & $69.01 \pm 16.68$ \\
\hline Leased & 273 & $69.20 \pm 19.49$ & $64.85 \pm 19.05$ & $68.08 \pm 17.50$ \\
\hline Other & 217 & $65.44 \pm 20.15$ & $60.62 \pm 19.28$ & $64.54 \pm 17.69$ \\
\hline P Value & & 0.002 & 0.001 & 0.006 \\
\hline \multicolumn{5}{|l|}{ Income, \$ } \\
\hline$<100$ & 342 & $64.15 \pm 18.99$ & $61.07 \pm 18.16$ & $63.72 \pm 16.64$ \\
\hline $100-300$ & 549 & $71.68 \pm 18.82$ & $66.84 \pm 18.41$ & $70.50 \pm 16.67$ \\
\hline$>3000$ & 97 & $67.26 \pm 21.43$ & $65.94 \pm 17.60$ & $66.59 \pm 19.24$ \\
\hline P Value & & 0.001 & 0.001 & 0.001 \\
\hline Total & 988 & $68.64 \pm 19.45$ & $64.75 \pm 18.42$ & $67.77 \pm 17.20$ \\
\hline
\end{tabular}

${ }_{\mathrm{a}}$ Abrreviations: MCS: mental component summary; PCS: physical component summary.
${ }^{\mathrm{b}}$ Data are presented as mean $\pm S \mathrm{~S}$. 
Aghayan Set al.

\begin{tabular}{lccccc}
\hline \multicolumn{1}{l}{ Table 3. Linear Regression Using SEM Relationships Among Quality of Life and Gender and Socioeconomic Status ${ }^{\mathrm{a}}$} \\
\hline Variables & Coefficient & Standardized Coefficients & SE & P Value & 95\% CI \\
\hline Gender & -7.96 & -0.11 & 2.4 & 0.001 & $-12.86-3.25$ \\
SES & 4.09 & 0.18 & 1.1 & $<0.001$ & $2.03-6.15$ \\
Cons & 76.17 & 4.4 & 29.4 & $<0.001$ & $71.08-81.026$ \\
Variance (quality of life) & 281.20 & - & 12.9 & - & $256.92-307.79$ \\
\hline
\end{tabular}

a Abbreviations: SES, socioeconomic status; CI, confidence interval.

\section{Discussion}

In this study, $94.5 \%$ of the participants were men, which is consistent with the higher number of men in other studies $(17,18)$. Perhaps one of the reasons for the higher number of men is the higher prevalence of addiction among men, as well as the fewer referring of women to self-introduction centers. In our study, a significant relationship was observed between quality of life and occupation so that employed participants showed higher levels of life quality which is in line with the findings of Hojjati and colleagues (29). In a cross-sectional study, 3005 addicted person were reviewed to assess the demographic characteristic, prototype of drug consumption, and its relation with some personal and social variation in Gorgan (northeast, Iran); $61.7 \%$ of the subjects were either unemployed or without any real job (18). Unemployment and the financial problems which result from the addicts' lack of role in the family and society reduce the quality of life in the addicts.

The result of our study showed a significant relationship between education and quality of life which is consistent with the findings of Timareh and colleagues on diabetes patients (30). Perhaps lower levels of education and fewer learning opportunities and facilities predispose people more toward substance abuse and as a result higher prevalence of addiction among them.

The mean score of quality of life of addicts was 67.8. A significant relationship was also observed between gender and quality of life which is consistent with the results of a study by Gonzales et al. (27). The higher level of quality of life for men in the present study is also in accord with the findings of Hojjati and colleagues (29).

The quality of life score in the addicts who referred to methadone maintenance treatment centers was more than $50 \%$ which is in line with the study by Hojjati and colleagues (29). Some studies indicate a lower level of quality of life for addicts in comparison to that of normal people $(12,15,16,20-22,29)$ and some other studies showed the positive effect of methadone and buprenorphine maintenance treatment on the improvement of health related quality of life of addicts after they refer to treatment centers $(14,19,23-26)$. In a descriptive study which has been done in a cohort and longitudinal manner during 3 months (from the beginning and 3 months after entrance) the quality of life of 33 addicts has been assessed. The result of this study showed that detoxification has been effective in improving their quality of life
(31). Hoseinifar et al. (32) compared the quality of life and mental health between addicts and non-addicts. They showed that addicts live in the worst condition and need strong support and their quality of life was lower than of non addicts. The present results indicate that people who are under treatment in these centers have higher scores, which is in line with another study done in Shahroud on the quality of life of non addicts (33). Perhaps one reason for the lack of difference between the quality of life of addicts and non-addicts is the effect of maintenance treatment. Karow et al, in a longitudinal investigation of health-related quality of life in patients with severe opioid dependence, showed that health-related quality of life (HRQOL) is associated with a successful treatment in opioid addiction (1).

About $64.7 \%$ of participants were city-dwellers and the rest were villagers. A significant relationship was observed between quality of life and place of residence so that those living in village showed a lower score in all aspect of life quality.

One limitation of this study was the dearth of relevant studies which could help discuss and compare our findings. Moreover due to cultural issues, women do not tend to refer to treatment centers, so fewer numbers of women were studied. Also, we recommend evaluation of the participants before and after maintenance treatments, so we could have a better assessment of addicts' QOL.

Although in most studies, the quality of life of drug dependent people was reported to be low, participants in this study showed a higher level of life quality and since all participants were receiving methadone or buprenorphine treatment, it seems that MMT centers could improve the quality of life of the addicts. Therefore, expanding such centers can play a significant role in improving the quality of life of the addicts.

The results of the study also suggest that more service should be provided to people with lower socioeconomic status. Moreover, establishing treatment centers for women can encourage more voluntary reference to these centers by women and accordingly would lead to the improvement of their quality of life.

\section{Acknowledgments}

We are grateful to the subjects participated in the study. 


\section{Footnotes}

Authors' Contribution:Shahrokh Aghayan, Reza Chaman, Mohammad Amiri, and Ahmad Khosravi contributed to the study concept, design, data gathering, data analysis, interpretation of data, and drafting the manuscript. Funding/Support:This project was supported by Shahroud University of Medical Sciences (grant No: 9071).

\section{References}

1. Karow A, Reimer J, Schafer I, Krausz M, Haasen C, Verthein U. Quality of life under maintenance treatment with heroin versus methadone in patients with opioid dependence. Drug Alcohol Depend. 2010;112(3):209-15. doi: 10.1016/j.drugalcdep.2010.06.009. [PubMed: 20728288]

2. Ghahramani L, Nazari M, Mousavi M. Improvement of quality of life in elderly men in kahrizak nursing home based on educational intervention. Knowl Health J. 2009;4(2):18-23.

3. Carr AJ, Thompson PW, Kirwan JR. Quality of life measures. Br J Rheumatol. 1996;35(3):275-81. [PubMed: 8620304]

4. Conger SA, Moore KD. Chronic illness and quality of life: the social workers role. New York; TSAO foundation: 2002.

5. Kamali M, Arjmand H, AhangarI M. A Study of quality of life among older people with hypertension and low back pain. Saalmand. 2008;3(7):26-32.

6. Brunner LS, Smeltzer SC, Bare BG, Hinkle JL, Cheever KH. Brunner $\&$ Suddarth's Textbook of Medical-Surgical Nursing. Philadelphia: Lippincott Williams \& Wilkins; 2010.

7. Darvishpoor Kakhki A, Abed Saeedi J, Delavar A. Tools for measurement of health status and quality of life of elderly people. Pejouhesh. 2010;33(3):162-73.

8. Park K. Park's textbook of preventive and social medicine. 21st ed. Jabalpur: Banarsidas Bhanot Publishers; 2011.

9. King AC, Pruitt LA, Phillips W, Oka R, Rodenburg A, Haskell WL. Comparative effects of two physical activity programs on measured and perceived physical functioning and other health-related quality of life outcomes in older adults. J Gerontol A Biol Sci Med Sci. 2000;55(2):M74-83. [PubMed:10737689]

10. Leidy NK, Revicki DA, Geneste B. Recommendations for evaluating the validity of quality of life claims for labeling and promotion. Value Health. 1999;2(2):113-27. doi: 10.1046/j.15244733.1999.02210.x. [PubMed: 16674343]

11. Barbotte E, Guillemin F, Chau N, Lorhandicap G. Prevalence of impairments, disabilities, handicaps and quality of life in the general population: a review of recent literature. Bull World Health Organ. 2001;79(11):1047-55. [PubMed: 11731812]

12. Kaplan HI, Sadock BJ. Synopsis of psychiatry: Behavioral sciences clinical psychiatry. Philadelphia: Williams \& Wilkins Co; 1998.

13. Katibaei J, Hamidi H, Yarian S, Ghanbari S, PS SM. Comparison of quality of life, stress and mental health of addicts and nonaddicts affected by HIV and healthy individuals.J Behav Sciences. 2010;4(2):17-8.

14. Sadock BJ, Sadock VA, Ruiz P. Comprehensive textbook of psychiatry. 7th ed. Philadelphia: Williams and wilkins; 2000.

15. Esfandabad HS, Nejadnaderi S, Emamipour S. Assessment of quality of life and psychological disorder symptoms among opium - dependent men on buprenorphine detoxification. Procedia - Soc Behav Sci. 2010;5:1396-9. doi:10.1016/j.sbspro.2010.07.295.

16. Bizzarri J, Rucci P, Vallotta A, Girelli M, Scandolari A, Zerbetto E, et al. Dual diagnosis and quality of life in patients in treatment for opioid dependence. Subst Use Misuse. 2005;40(12):1765-76. [PubMed:16419555]
17. Smith KW,Larson MJ. Quality of life assessments by adult substance abusers receiving publicly funded treatment in Massachusetts. Am JDrug Alcohol Abuse. 2003;29(2):323-35. [PubMed:12765209]

18. Abbasi A, Taziki SA, Moradi A. Pattern of substance abuse based on demographic factors in drug users represents their city of Gorgan.J Gorgan Univ Med Sci. 2006;8(1):21-7.

19. Amiri M, Khosravi A, Chaman R. Drug Abuse Pattern and High Risk Behaviors among Addicts in Shahroud County of Semnan Province, Northeast Iran in 2009. J Res Health Sci. 2010;10(2):1049. [PubMed: 22911932]

20. Calsyn DA, Saxon AJ, Bush KR, Howell DN, Baer JS, Sloan KL, et al. The Addiction Severity Index medical and psychiatric composite scores measure similar domains as the SF-36 in substance-dependent veterans: concurrent and discriminant validity. Drug Alcohol Depend. 2004;76(2):165-71. doi:10.1016/j.drugalcdep.2004.04.018. [PubMed:15488340]

21. Yen CN, Wang CS, Wang TY, Chen HF, Chang HC. Quality of life and its correlates among heroin users in Taiwan. Kaohsiung $J$ Med Sci. 2011;27(5):177-83. doi: 10.1016/j.kjms.2010.09.003. [PubMed: 21527184]

22. Schrimshaw EW, Siegel K. Perceived barriers to social support from family and friends among older adults with HIV/AIDS. $J$ Health Psychol. 2003;8(6):738-52. doi: 10.1177/13591053030086007. [PubMed:14670207]

23. te Vaarwerk MJ, Gaal EA. Psychological distress and quality of life in drug-using and non-drug-using HIV-infected women. Eur J Public Health. 2001;11(1):109-15. [PubMed: 11276564]

24. Batki SL, Canfield KM, Smyth E, Ploutz-Snyder R. Health-related quality of life in methadone maintenance patients with untreated hepatitis C virus infection. Drug Alcohol Depend. 2009;101(3):17682. doi:10.1016/j.drugalcdep.2008.12.012. [PubMed:19233573]

25. Maremmani I, Pani PP, Pacini M, Perugi G. Substance use and quality of life over 12 months among buprenorphine maintenance-treated and methadone maintenance-treated heroin-addicted patients. J Subst Abuse Treat. 2007;33(1):91-8. doi: 10.1016/j. jsat.2006.11.009. [PubMed: 17588494]

26. Nosyk B, Guh DP, Sun H, Oviedo-Joekes E, Brissette S, Marsh DC, et al. Health related quality of life trajectories of patients in opioid substitution treatment. Drug Alcohol Depend. 2011;118(2-3):25964. doi: 10.1016/j.drugalcdep.2011.04.003. [PubMed:21546173]

27. Gonzales R, Ang A, Marinelli-Casey P, Glik DC, Iguchi MY, Rawson RA, et al. Health-related quality of life trajectories of methamphetamine-dependent individuals as a function of treatment completion and continued care over a 1-year period.J Subst Abuse Treat. 2009;37(4):353-61. doi:10.1016/j.jsat.2009.04.001. [PubMed: 19553066]

28. Montazeri A, Goshtasebi A, Vahdaninia M, Gandek B. The Short Form Health Survey (SF-36): translation and validation study of the Iranian version. Qual Life Res. 2005;14(3):875-82. [PubMed:16022079]

29. Hojjati H, Aloustani S, Akhondzadeh G, Heidari B, SHARIFNIA H. Study of mental health and its relation with quality of life in addicts. J Shahid Sadoughi Univ Med Sci Health Serv. 2010;18(3):207-14.

30. Timareh M, Rhimi M, Abbasi P, Rezaei M, Hyaidarpoor S. Quality of life in diabetic patients referred to the Diabete research Center in Kermanshah. J Kermanshah Univ Med Sci. 2012;16(1):63-9.

31. Tavakoli M. the influence of detoxification on the quality of life in substance addicts lives with 40-65 years of age referring to the charity “ongress60. Iran J Ageing. 2012;6(23):34-40.

32. Hoseinifar J, Zirak SR, Shaker A, Meamar E, Moharami H, Siedkalan MM. Comparison of Quality of Life and Mental Health of Addicts and Non- Addicts. Procedia - Soc Behav Sci. 2011;30:1930-4. doi:10.1016/j.sbspro.2011.10.375.

33. Amiri M, Raei M. A study of the Life Quality of Students at a University of Medical Sciences in the Northeast of Iran. Knowl Health J. 2013;8(4):176-80. 